\title{
Forecasting Input Demand Shocks on China's Gross Value of Agricultural Output $^{+}$
}

\author{
Dayton M. Lambert and Seong-Hoon Cho*
}

\begin{abstract}
This paper applies recent developments in forecasting spatial process models to estimate the impact of input shocks on China's 1999 gross value added output (GVAO) in agriculture. A Cobb-Douglas production function allowing total factor productivity to vary across regions is used to forecast the geographic distribution of GVAO following shocks in input availability. Results suggest that GVAO will be similar to baseline levels following input shocks, but the differential gains experienced in some areas may correspond with losses in neighboring administrative units.
\end{abstract}

Key Words: China, Gross value-added agriculture, Spatial forecasting

JEL Classification: C21, R11, Q10

\section{INTRODUCTION}

The Chinese agricultural sector continues to grow with the country's economic expansion. Chemical fertilizer, pesticide, and machinery demand are rapidly increasing, and so too is the production cost share of these inputs. The cost share of chemical fertilizers increased from virtually none in 1952 to more than 12 percent of total production costs in 1995, and the machinery cost share increased from almost nothing in 1957 to more than 12 percent in 1997 (Fan 1997). Meanwhile, labor costs have steadily declined. Labor made up roughly 50 percent of agricultural production costs in the 1950s but in 1995, the labor cost share decreased to about 2.8 percent of production costs (Fan 1997).

The Statistical Bureau of China (SSB) reported that gross value of agricultural output (GVAO) increased 6.5 percent per year between 1979 and 1995, up from about a 2.8 percent increase per year between 1952 and 1978 (Statistical Bureau of China, 1996). Despite official reports of dramatic agricultural growth over the past several decades, recent research finds that labor productivity of Chinese agriculture lagged behind productivity growth compared to other sectors between 1987 and 1997 (Yang and Lahr, 2008, RRS this issue).

Some have also questioned the accuracy of output measures in official Chinese statistics (Zhong, 1997; Lu, 1998; Fuller, Hayes, and Smith, 2000), while others have suggested that the improvement in agricultural productivity during the 1980s may have been due to a reduction in labor availability in rural areas following market reform in the late 1970s (Cai, Wang, and Yang, 2002). Alternatively, decreases in the labor cost share from 50 percent in the 1950s to 28 percent in the 1990s may have more to do with recent increases in agricultural productivity, and less to do with increased use of capital intensive inputs. Rice and wheat yields for China surpass other producing regions, such as (respectively) Southeast Asia and North America (Figure 1). Corn

\footnotetext{
${ }^{+}$The authors would like to thank the editors and two anonymous reviewers for their helpful comments, and Harwood Shaffer for providing perspectives on China and trade. The views expressed here do not necessarily represent those of the University of Tennessee.

* Dayton Lambert and Seong-Hoon Cho (contact author) are Assistant Professors with the Department of Agricultural Economics, University of Tennessee, 2621 Morgan Circle, 314-A Morgan Hall, Knoxville, TN 37996-4518. E-mail: scho9@utk.edu.
}

(C) Southern Regional Science Association 2010.

ISSN 1553-0892

SRSA, 1601 University Avenue, PO Box 6025, Morgantown, West Virginia 26506-6025, USA. 
and soybean yields remain relatively low, but yield productivity continues to increase, paralleling gains in other major soybean and corn producing regions. Since 2000, while harvested acres of rice and wheat have decreased, rice and wheat yields have increased, and China is now a net exporter of these commodities (Ray, 2008).

Demand for oil seed crops is growing due to increasing domestic demand, particularly for oilseed meal used in livestock production and oil for human consumption. With the rise in the real price of crude oil, demand for biofuels is likely to increase as the country strives to meet growing energy demand, which may further intensify domestic demand for oilseed or other dedicated energy crops. Indeed, parastatal companies are positioned to meet these challenges with patented technologies converting hemicellulose to functional sugars for the production of ethanol or other value-added products (e.g., Shandong's Longlive Bio-technology, Ltd., longlivegroup.en.alibaba. com, among many others). Demand for meat, especially pork and poultry, has also increased with the rising real income of many Chinese, which in turn has increased demand for feed grains produced at home or imported from abroad (Tian and Chudleigh, 1999; Guo, Popkin, and Zhai, 2000; Hsu, Chern, and Gale, 2001). China imports about 25 percent of the world's soybean exports, a 20 percent increase since 2000 (USDA FAS, 2008, http://www.fas.usda.gov). On the domestic front, in order to meet these demand challenges, farmers are planting higher-yielding grain varieties, reducing input costs with no-till corn/wheat rotations, multicropping poplar with row crops, and increasing chemical input use.

It seems inevitable that the structure of Chinese agriculture will continue to change as the mid-1990s reform of the hukou system continues, and residents that live in rural areas leave the countryside to pursue new job opportunities in the cities (Carter and Rozelle, 2001). The migration of rural citizens to urban centers is coincident with China's agricultural transformation. As adoption of new production technologies continues to advance, labor productivity in the agricultural sector will increase, which in turn will increase agricultural output at the same or lower cost. This shift is likely to occur faster than in the recent past for a variety of reasons, including stronger demand-pull for agricultural products and access to more off-farm work opportunities in the manufacturing or service sectors in urban locations (Wisner, 2000).

FIGURE 1. Comparison of China's Yield of Rice, Wheat, Corn, and Soybeans

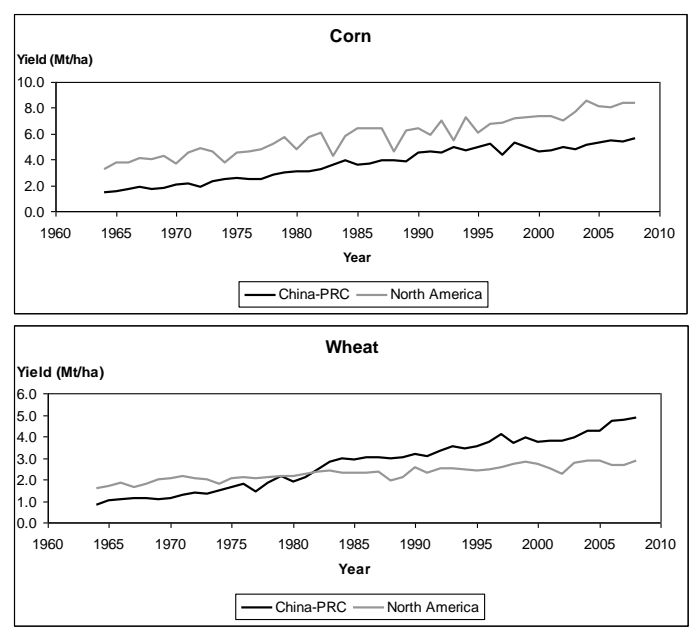

Source: USDA FAS (2008)

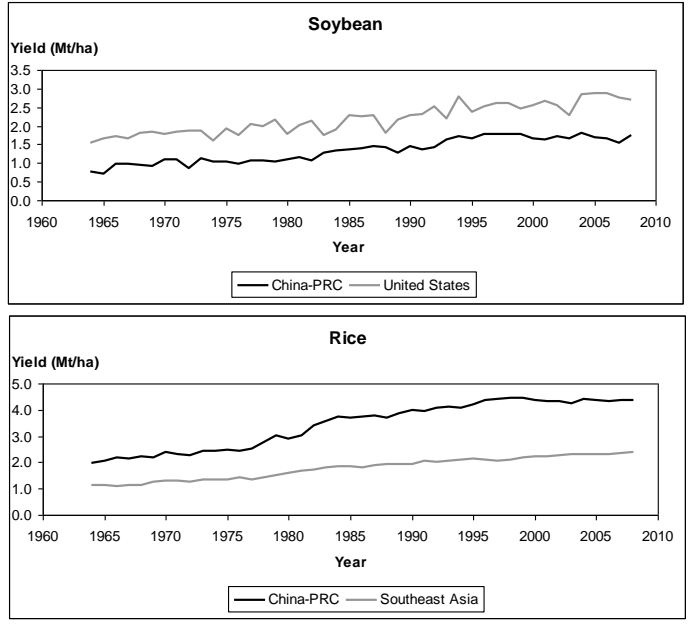

- China-PRC — Southeast Asia

Southern Regional Science Association 2010. 
The ability of China's agricultural sector to meet these challenges is optimistic but uncertain over the long run. Nonetheless, China's GVAO is anticipated to grow faster in coming years, and the nation is expected to remain a major force in world food markets in the future (Carter and Rozelle, 2001). Given recent trends in increased chemical and machinery use, it also seems likely that demand for capital intensive inputs will continue to rise, slowly replacing labor. It therefore remains important to anticipate the future growth of the agricultural sector because most of its interindustry relationships inside China remain largely forwardly linked, especially in emerging value-added enterprises specializing in production of intermediate agricultural products for domestic consumption and export markets. Even though the availability of agricultural machinery and chemical fertilizer has increased and access to more off-farm work opportunities has eroded farm labor availability in some regions, agriculture remains an important source of income for millions of rural inhabitants. Estimates of the changes in agricultural production due to changes in input use and availability are therefore important for making informed policy and planning decisions involving the agriculture sector, its supporting sectors, and other sectors using agricultural products as intermediate inputs. However, the extent to which these trends will affect GVAO at regional and county levels and the degree to which these changes are functionally linked across space remains unclear.

This paper applies recent developments in forecasting spatial process models in order to estimate changes in the geographic distribution of GVAO following an input shock in each of China's seven regions. The econometric approach applies recent developments from the spatial econometric literature that facilitate estimation of spatial process models when disturbances are heteroskedastic. Given consistent estimates of a "meta" production function, a series of simulations increasing (or decreasing) input use generate spatial forecasts of GVAO, which are in turn compared to a baseline expected GVAO. The spatial predictor is estimated using a recently developed approach suggested by Kelejian and Prucha (2007).

The empirical model is discussed in the next section, followed by discussion of the econometric issues and details on the procedure used to generate forecasts of the spatial process model. Results and discussion follow, and the last section concludes.

\section{EMPIRICAL MODEL}

A Cobb-Douglas production function ${ }^{1}$ is hypothesized to represent China's gross value added output (GVAO);

$$
y_{i}=\gamma \prod_{k=1}^{M} x_{i k}^{\beta_{k}},
$$

where, for administrative unit ("county") county $i, y_{i}$ is GVAO; $x_{i k}$ are factors of production $(k=$ $1, \ldots, 3)$ including agricultural labor, mechanical power, and fertilizer; $\gamma$ is total factor productivity; and $\beta_{k}$ are coefficients corresponding with input $k$. Equation (1) is modified to reflect potentially correlated production between administrative units,

\footnotetext{
${ }^{1}$ We considered more general forms of the Cobb-Douglas production function (i.e., a constant elasticity of substitution [CES] production function), but because of estimation problems arising from the nonlinearity of the CES production function, the results of the more general forms are not available.
} 


$$
y_{i}=\gamma \prod_{\substack{j=1 \\ i \neq j}}^{n} y_{j}^{\lambda_{\text {Lag }} w_{i j}} \prod_{k=1}^{M} x_{i k}^{\beta_{k}},
$$

where $w_{i j}$ is an element of an exogenous $n$ by $n$ matrix ( $n$ being the number of locations) identifying county neighborhoods, and $\lambda_{\text {Lag }}$ is a spatial lag autoregressive coefficient. Many regional analyses focusing on population or economic growth interpret so-called lagged autoregressive processes as measuring economic spillovers among cross-sectional units (e.g., Bao, Henry, and Barkley, 2004; Moreno et al., 2004; Boarnet, Chalermpong, and Geho, 2005; Lambert et al., 2006; McGranahan et al., 2006; Cho et al., 2007; Monchuk et al., 2007). Significant lag correlation between spatial units suggests that economic growth in one location depends on, or is explained by, economic growth in neighboring cross-sectional units. These interactions signal possible information spillovers, thick labor markets, access to relatively larger demand markets, or forward-backward economic linkages across space in general (Anselin, 2003; Moreno et al., 2004). Most of the above studies relate to socio-demographic and economic processes in Western societies, and typically assume that the data generating process is grounded in free market economy principles including firm cost minimization, utility maximization by individuals, price taking behavior, and prices adjusting to clear markets. In China's case, these assumptions may be less tenable because of its centralized planning authority. Although recent macro-economic reforms may have set the course for competitive domestic markets at the local and regional levels, government intervention remains in agriculture through various means. Therefore, while it may be difficult to apply conventional economic inference in terms of profit maximizing producers as related to input use and agricultural productivity, general assertions about regional comparative advantage with respect to agricultural fertility or other resource endowments can still be hypothesized. Indeed, by including such correlated information into the empirical model, more accurate forecasts are possible. In this context, significant positive correlation between GVAO proxy clusters of administrative units, which we refer to as "counties", exhibiting regional comparative advantage with respect to agricultural productivity.

Total factor productivity is allowed to vary across regions by modifying (2),

$$
y_{i}=\gamma_{r} \prod_{\substack{j=1 \\ i \neq j}}^{n} y_{j}^{\lambda_{\text {Lag }} w_{i j}} \prod_{k=1}^{M} x_{i k}^{\beta_{k}},
$$

where $\gamma_{r}$ measures total factor productivity in region $r$ ( $r=$ East, South, Southwest, North, Northwest, Northeast, and Central). When production is stochastic, Equation (3) is:

$$
y_{i}=\gamma_{r} \prod_{\substack{j=1 \\ i \neq j}}^{n} y_{j}^{\lambda_{\text {Lag }} w_{i j}} \prod_{k=1}^{M} x_{i k}^{\beta_{k}} \varepsilon_{i},
$$

where $\varepsilon_{i}$ is a random shock. Deviations from the iid assumption with respect to the disturbances suggest the following autoregressive error process;

$$
\varepsilon_{i}=u_{i} \prod_{\substack{j=1 \\ i \neq j}}^{n} \varepsilon_{j}^{\lambda_{E n r o r} w_{i j}}
$$

with $u_{i}$ lognormally distributed as $\sim \operatorname{iid}(\mathbf{0}, \boldsymbol{\Omega})$, with $\mathrm{E}\left[\mathbf{u u ^ { \prime }}\right]=\boldsymbol{\Omega}$. The error structure is anticipated when input levels of neighboring counties are correlated. For example, the application levels of 
fertilizer may be similar between neighboring counties because they are located in relatively fertile regions, or labor may be highly concentrated in a given county (e.g., provincial capitals), which may in turn be surrounded by a halo of counties with relatively low population densities. Not accounting for potential geographic interdependencies may result in omitted variable bias (Anselin and Florax, 1995; Anselin, 2003).

Taking the natural log of both sides of (4) and assuming the error structure of (5) yields an estimable log-log linear equation:

$$
\begin{gathered}
\ln \left(y_{i}\right)=\ln \left(\gamma_{r}\right)+\lambda_{\text {Lag }} \sum_{\substack{j=1 \\
i \neq j}}^{n} w_{i j} \ln \left(y_{j}\right)+\sum_{k=1}^{M} \beta_{k} \ln \left(x_{i k}\right)+\ln \left(\varepsilon_{i}\right), \\
\ln \left(\varepsilon_{i}\right)=\lambda_{E r r o r} \sum_{\substack{i \neq j \\
j=1}}^{n} w_{i j} \ln \left(\varepsilon_{j}\right)+\ln \left(u_{i}\right)
\end{gathered}
$$

or, in more general notation; $\mathbf{y}=\lambda_{\text {Lag }} \mathbf{W y}+\mathbf{x} \boldsymbol{\beta}+\mathbf{e}, \mathbf{e}=\lambda_{\text {Error }} \mathbf{W e}+\mathbf{u}$, which is the usual spatial autoregressive model with autocorrelated disturbances of order $(1,1)$ (SARAR(1,1), Anselin and Florax, 1995, discussed below). Regional differences in total factor productivity $\left(\ln \left[\gamma_{r}\right]\right)$ are measured by including regional dummy variables in (6).

\section{DATA}

Data for per hectare use of labor, mechanical power, and fertilizer at the administrative level were collected from a county-level socio-economic survey conducted by the Statistical Bureau of China (SSB 2000). SSB is the official government agency that collects, measures, and reports demographic and agronomic statistics in China. This dataset was used by Cho et al. (2007) and Cho, Chen, and Poudyal (2010) in a study of spatial structure of county-level agricultural production. Data for the 1,891 of 2,159 administrative units collected in 1999 were used in this study, after excluding observations with missing values. The SSB collected agricultural survey data in 1992, 1995, and 1999. The last survey conducted in 1999 was the most complete and recent information at the county level. Ideally, data that are more current would have been used, and county data beyond 1999 are available from some provincial statistical offices. Panel data also would be most desirable. However, time and limited resources were obstacles in obtaining data that were more recent. Thus, the results presented provide only a cross-sectional snapshot of the local input use and gross value added agricultural productivity in 1999.

The SSB reports gross value added agricultural output (GVAO) as the sum of the value of production of all agricultural products produced by the sector. The production value of a product is calculated by multiplying quantity by price (Fan and Zhang, 2002). The GVAO's used in this study are measured in current prices. Labor represents the number of equivalent persons engaged in agricultural production during the year. Mechanical power is the sum of the power of all agricultural machinery in watts. Applied chemical fertilizer is calculated by converting the gross weight into weight containing 100 percent effective components (i.e., 100 percent nitrogen content in nitrogenous fertilizer, 100 percent phosphorous pentoxide contents in phosphate fertilizer, 100 percent potassium oxide contents in potash fertilizer). All variables are normalized by county size in hectares. 
TABLE 1. Global and Regional Geometric Means of Key Study Variables

\begin{tabular}{lrrrrrrrr}
\hline \hline & \multicolumn{2}{c}{$\begin{array}{c}\text { GVAO } \\
\text { (\$/hectare) }\end{array}$} & \multicolumn{2}{c}{$\begin{array}{c}\text { Labor } \\
\text { (persons/ hectare) }\end{array}$} & \multicolumn{2}{c}{$\begin{array}{c}\text { Machinery } \\
\text { (watt/ hectare) }\end{array}$} & \multicolumn{2}{c}{$\begin{array}{c}\text { Chemical fertilizer } \\
\text { (ton/ hectare) } \\
\text { Region }\end{array}$} \\
mean & std dev & mean & std dev & mean & std dev & mean & std dev \\
\hline Nation & $1,183.21$ & $(730.29)$ & 1.96 & $(1.11)$ & $2,453.06$ & $(1,814.42)$ & 0.21 & $(0.14)$ \\
East & $1,502.50$ & $(523.33)$ & 2.15 & $(0.78)$ & $2,977.43$ & $(1,723.41)$ & 0.27 & $(0.13)$ \\
North & 879.27 & $(774.22)$ & 1.47 & $(0.93)$ & $4,172.43$ & $(3,357.23)$ & 0.19 & $(0.14)$ \\
Northeast & $1,176.64$ & $(13.24)$ & 1.13 & $(0.72)$ & $2,121.78$ & $(914.28)$ & 0.19 & $(0.11)$ \\
Northwest & 819.81 & $(492.88)$ & 1.53 & $(0.89)$ & $2,129.54$ & $(1,505.46)$ & 0.18 & $(0.14)$ \\
South & $2,536.93$ & $(978.43)$ & 2.30 & $(0.83)$ & $2,150.36$ & $(1,219.02)$ & 0.28 & $(0.16)$ \\
Southwest & $1,143.71$ & $(45.30)$ & 2.89 & $(0.79)$ & $1,634.92$ & $(1,121.44)$ & 0.16 & $(0.11)$ \\
Central & $1,339.07$ & $(411.03)$ & 2.46 & $(0.88)$ & $2,577.83$ & $(1,575.07)$ & 0.26 & $(0.10)$ \\
\hline \hline
\end{tabular}

Missing observations (one or more key statistics not reported in the SSB dataset) mostly occur in the Xizang (Tibet) and Qinghai provinces. These missing observations are from counties that were likely not heavily engaged in agricultural production, or were simply counties where information was not available. Xizang and Qinghai account for relatively small percentages $(0.2$ and 0.4 percent respectively), of the nation's population and produce a small portion of its agricultural output. The sample statistics for the agricultural input and output variables are reported in Table 1 . The average county employs around 2 agricultural laborers per hectare, uses 2,453 watts per hectare of mechanical power, applies 0.2 tons of chemical fertilizer per hectare, and produces $\$ 1,183$ per hectare worth of agricultural products.

\section{ESTIMATION PROCEDURES}

An increasing number of applied studies in geography, economics, and regional science incorporate the spatial dimension of population and economic growth in regression models (e.g., Bao, Henry, and Barkley, 2004; Moreno et al., 2004; Boarnet, Chalermpong, and Geho, 2005; Cohen and Paul, 2005; Cho et al., 2007; Monchuk et al., 2007; Lambert et al., 2007; Anselin and Lozano-Gracia, 2008). Most use a spatial process model, due to Whittle (1954), in which an endogenous variable specifies spatial interactions between cross-sectional units plus a disturbance term. The interactions are modeled as a weighted average of nearby cross-sectional units, and the endogenous variable comprising the interactions is usually referred to as a spatially lagged variable. The weights in the matrix identify neighborhood connections, which differentiates spatial process models from other spatial econometric methods. Whittle's spatial autoregressive lag model (SAR) was popularized and extended by Cliff and Ord (1973, 1981), who distinguished models in which the disturbances follow a spatial autoregressive process.

\subsection{SARAR(1,1) Spatial Process Model}

The SARAR(1,1) (Anselin and Florax, 1995) contains a spatially lagged endogenous variable as well as spatially autoregressive disturbances in addition to exogenous variables; $\mathbf{y}=$ $\lambda_{\text {Lag }} \mathbf{W y}+\mathbf{X} \boldsymbol{\beta}+\boldsymbol{\varepsilon}, \boldsymbol{\varepsilon}=\lambda_{\text {Error }} \mathbf{W} \boldsymbol{\varepsilon}+\mathbf{u}, \mathbf{u} \sim \operatorname{iid}(\mathbf{0}, \boldsymbol{\Omega})$, where $\mathbf{W}$ is a matrix identifying spatial neighbors. This study uses a row standardized first order contiguity matrix to measure GVAO 
correlation between counties. The average number of neighbors was 5.29, with a standar deviation of 1.62. When the number of neighbors is unequal (as determined by the spatial matrix), the disturbances are heteroskedastic and $E\left[\mathbf{u u}^{\prime}\right]=\boldsymbol{\Omega}$ (Anselin, 2003). The reduced form of the SARAR spatial process model is $\mathbf{y}=\mathbf{A}^{-1} \mathbf{X} \boldsymbol{\beta}+\mathbf{A}^{-1} \mathbf{B}^{-1} \mathbf{u}$, with the "Leontief" inverses, $\mathbf{A}^{-1}=$ $\left(\mathbf{I}-\lambda_{\text {Lag }} \mathbf{W}\right)^{-1}$ and $\mathbf{B}^{-1}=\left(\mathbf{I}-\lambda_{\text {Error }} \mathbf{W}\right)^{-1}$. These terms distinguish this class of spatial process models from other econometric models. These matrices relay feedback and feed-forward effects of shocks between locations. When the spatial weights are contiguity matrices or clusters of observations bounded by some metric, shocks originating locally are transmitted to all other locations and decay with distance. In other words, the SARAR $(1,1)$ is a global model of spatial lag and error autocorrelation.

\subsection{Model Estimation}

Estimation of the SARAR(1,1) process model follows Kelejian and Prucha's (2010) general moments procedure. The minimum distance procedure used to estimate the error autoregressive parameter $\left(\lambda_{\text {Error }}\right)$ yields an efficient and consistent estimator when disturbances are heteroskedastic. In addition, the estimation method provides a relatively straightforward procedure to test the joint hypothesis $\lambda_{\text {Lag }}=\lambda_{\text {Error }}=0$. The covariance estimator is also robust to unspecified forms of heteroskedasticity.

\subsection{Direct and Total Effects of the SARAR(1,1) Spatial Process Model}

The lag Leontief inverse connecting spatial units suggest that the marginal effects of the SARAR $(1,1)$ model can be decomposed into their 'direct', 'indirect', and 'induced effects' on GVAO (Abreu, de Groot, and Florax 2004). The geometric sum of these effects are the 'total effect', estimated as $\hat{\beta}_{k}^{\text {Total }}=\hat{\beta}_{k}\left(1-\hat{\lambda}_{\text {Lag }}\right)^{-1}$, which accounts for the spillover effects of GVAO production in one spatial unit on neighboring counties (Anselin and Lozano-Gracia 2008). The delta method (Greene 1997) is applied to estimate the total effect standard errors.

\subsection{Spatial Forecasting of Agricultural Output with the SARAR(1,1) Estimator}

Generating spatial predictions of economic growth using econometric results may supplement a broader set of tools policy makers could use to gauge the impact of policies on local economies in regional contexts. In a sensitivity analysis, we forecast the administrativelevel GVAO across China's regions with the SARAR $(1,1)$ estimates following an increase in machinery and fertilizer use by 15 percent, 25 percent, and 35 percent, and (correspondingly) a change in labor availability of 0 percent, -5 percent and -15 percent. The simulation levels are based on use trends for agricultural fertilizer, machinery use, and changes in labor availability between 1990 and 1995 (Fan, 1997). Labor availability declined by 3 percent, and chemical fertilizer and machinery use increased by 33 percent and 25 percent, respectively, during this five year period.

We apply an unbiased and efficient predictor of the $\operatorname{SARAR}(1,1)$ model in the simulation (Kelejian and Prucha, 2007). The estimator is efficient because it incorporates information about the correlation between the spatially lagged dependent variable and the error term. Kelejian and Prucha demonstrated why two "intuitive predictors"; $\hat{\mathbf{y}}=\hat{\mathbf{A}}^{-1} \mathbf{X} \hat{\boldsymbol{\beta}}$ and $\hat{\mathbf{y}}=\hat{\lambda}_{\text {Lag }} \mathbf{W y}+\mathbf{X} \hat{\boldsymbol{\beta}}$ (with " $\wedge$ " denoting estimated values), are suboptimal. These candidates are biased because they ignore information about lag and error correlation between cross-sectional units. One example of a "full information" unbiased predictor suggested by Kelejian and Prucha (2007) is, 


$$
\begin{aligned}
& \hat{y}_{i}=\hat{\lambda}_{L a g} \sum_{\substack{i \neq j \\
j=1}}^{n} w_{i j} y_{j}+\mathbf{x}_{i}^{\prime} \hat{\boldsymbol{\beta}}+\operatorname{cov}\left(u_{i}, y_{-i}\right) \hat{\mathbf{V}}^{-1}\left[\mathbf{S}_{-i}\left(\mathbf{y}-\hat{\mathbf{A}}^{-1} \mathbf{X} \hat{\boldsymbol{\beta}}\right)\right], \text { with } \\
& \operatorname{cov}\left(u_{i}, y_{-i}\right)=\hat{\sigma}_{\varepsilon}^{2} \sigma_{i .}^{u}\left(\mathbf{I}-\hat{\lambda}_{\text {Lag }} \mathbf{W}^{\prime}\right)^{-1} \mathbf{S}_{-i}^{\prime}\left(\sigma_{i .}^{u} \text { is the } i \text { th row of } \hat{\mathbf{B}}^{-1} \hat{\mathbf{B}}^{\prime-1}\right), \text { and } \\
& \hat{\mathbf{V}}=\sigma_{\varepsilon}^{2} \mathbf{S}_{-i} \hat{\mathbf{A}}^{-1} \hat{\mathbf{B}}^{-1} \hat{\mathbf{B}}^{\prime-1} \hat{\mathbf{A}}^{\prime-1} \mathbf{S}_{-i}^{\prime}\left(\hat{\sigma}_{\varepsilon}^{2}=n^{-1} \hat{\boldsymbol{\varepsilon}}^{\prime} \hat{\boldsymbol{\varepsilon}}\right) .
\end{aligned}
$$

The matrix $\mathbf{S}_{-i}$ is an $n-1$ by $n$ "selection matrix," which is similar to an identity matrix except that the $i$ th row is eliminated.

Empirical distributions of the simulated GVAO are compared to the baseline predicted values to gauge the impact of increased input use and changes in labor availability on the spatial distribution of China's GVAO. The baseline values are generated using the estimated parameters and the observed input levels. An ex post spatial cluster analysis examines the spatial distribution of the forecasts using local Moran's I statistics (or Local Indices of Spatial Association; LISA's, Anselin, 1995). In discussion of the results, median values of the differences between the regionspecific baseline predictions are compared with the predicted GVAO values following a 25 percent increase in fertilizer and machine capacity and a 5 percent decrease in labor availability. These points were chosen because they roughly approximate the trends in input use reported by Fan (1997). The assumed decline in labor availability by 5 percent is a high-end estimate compared to the recent downward trend of 3 percent. The change in fertilizer and machinery use of 25 percent is a low-end estimate for changes in fertilizer use but is similar to observed changes in machinery use witnessed in the early 1990s.

\section{RESULTS AND DISCUSSION}

\subsection{Model Selection}

The Cobb-Douglas SARAR(1,1) specification with regional fixed effects explained about 34 percent of the variation in the data (Table 2). The null hypothesis of spatial independence $\left(\lambda_{\text {Lag }}=\lambda_{\text {Error }}=0\right)$ between county agricultural production and local production shocks was rejected in the Cobb-Douglas specification (Wald test $=106.49$, degrees of freedom $[\mathrm{df}]=2$ ). GVAO in one county is positively correlated with GVAO in other counties $\left(\lambda_{\text {Lag }}=0.67\right)$, which is consistent with the spatial pattern observed in the raw GVAO data (Figure 2, Moran's $I=0.65$, $\mathrm{P}=0.002$ ). Clustering of agriculture productivity may be due to geographical comparative advantage in production of a variety of agricultural commodities, perhaps related to soil fertility patterns, technology diffusion, labor clusters, or other resource endowments used in agriculture. Production shocks in one county are negatively associated with shocks in neighboring counties, albeit moderately $\left(\lambda_{\text {Error }}=-0.06\right)$. In locations where the expected value of GVAO exceeded actual levels, other local factors excluded from the model are important (but unobservable, given data limitations) with respect to explaining production at that administrative unit. These counties are surrounded by other counties where the expected GVAO underestimates observed valueadded output in 1999. 
TABLE 2. Estimates for China's Gross Value Added Originating (GVAO) from Agricultural Production, 1999

\begin{tabular}{|c|c|c|c|c|}
\hline \multirow[b]{2}{*}{ Variable } & \multicolumn{2}{|c|}{ Direct Effect } & \multicolumn{2}{|c|}{ Total Effect } \\
\hline & Estimate & $t$ test & Estimate & $t$ test \\
\hline Constant & 2.316 & 4.720 & 7.029 & 14.694 \\
\hline $\ln ($ Labor density) & 0.065 & 2.837 & 0.196 & 2.943 \\
\hline $\ln ($ Energy watts/ha $)$ & 0.107 & 4.513 & 0.324 & 6.208 \\
\hline $\ln ($ Fertilizer tons/ha $)$ & 0.134 & 5.521 & 0.407 & 4.509 \\
\hline$\lambda_{\text {Lag }}$ & 0.671 & 10.066 & 0.671 & 10.066 \\
\hline$\lambda_{\text {Error }}$ & -0.058 & -2.300 & -0.058 & -2.300 \\
\hline \multicolumn{5}{|l|}{ Regional variables } \\
\hline East & 0.005 & 0.285 & 0.015 & 0.290 \\
\hline North & -0.161 & -4.521 & -0.488 & -4.845 \\
\hline Northeast & 0.050 & 1.429 & 0.152 & 1.465 \\
\hline Northwest & -0.092 & -2.706 & -0.279 & -3.278 \\
\hline South & 0.210 & 4.058 & 0.637 & 7.780 \\
\hline Southwest & 0.036 & 1.755 & 0.110 & 1.687 \\
\hline 1,891 & & & & \\
\hline Adjusted $R^{2} \quad 0.337$ & & & & \\
\hline
\end{tabular}

\subsection{Input Factors and Total Factor Productivity}

Table 2 reports the direct and total effects of the input factors and region-specific total factor productivity on GVAO estimated with the Cobb-Douglas specification. All input factors are positively associated with GVAO at the 1 percent level. Regional total factor productivity is also heterogeneous (Wald test $=130.62, \mathrm{df}=6$ ). After adjusting the Cobb-Douglas estimates and their standard errors for the spatially lagged effects of GVAO, the input factors are more strongly associated with GVAO, and the magnitude of the elasticities increased. The sum of the elasticities was 0.93, which was not significantly different from 1 (Wald statistic $=0.5158$, $p=0.4726$ ), suggesting that the production technology exhibited constant returns to scale in 1999.

Total factor productivity continues to play a significant role in explaining GVAO at the regional level (Table 2). Total factor productivity was highest in the Southern region (exp(7.67) $=\mathrm{RMB} 2,134 / \mathrm{ha}$ ), where rice and rapeseed are the dominant crops. South China has comparative advantage with respect to producing these high-demand crops in terms of a milder climate conducive to these crops. Total factor productivity was lowest in the North and Northwest regions $(\exp (6.54)=\mathrm{RMB} 692 / \mathrm{ha}$ and $\exp (6.75)=\mathrm{RMB} 854$ /ha, respectively), where grains, oilseed crops, and pulses dominate.

\subsection{GVAO Spatial Forecasts after Input Shocks}

Southern Regional Science Association 2010. 
The coefficients estimated with the Cobb-Douglas specification forecast the effects of a shock in input use or availability on GVAO (Figure 3, Panels A, B). The spatial forecasts of the baseline GVAO exhibited a highly correlated pattern across the regions (Moran's $I=0.81, p=$ 0.002), which closely approximates the clustering pattern of the raw GVAO values (Figure 2). The empirical distributions of the baseline predicted GVAOs were not different from any of the simulated empirical distributions (Kolomogorov-Smirnoff two-sample test, $p>0.05$, Figure 4). Given a 25 percent increase in fertilizer and machinery use, and a 5 percent decrease in labor availability, the median difference between the expected baseline GVAO and the GVAO estimated following the shock in the South is about 19.29 U.S. dollars/ha (USD/ha) (135.03 $\mathrm{RMB} / \mathrm{ha}$ ). Counties in the North and Northwest regions experienced a decrease of $6.59 \mathrm{USD} / \mathrm{ha}$ (46.13 RMB/ha) and 6.17 USD/ha (43.19 RMB/ha), respectively. These differences from the global median GVAO values were not significant at the 10 percent level. However, there were significant differences observed comparing the impact of the shocks as differences from the baseline expected GVAO at the global level and on a case-by-case level between regions (Table 3).

The median difference between the baseline and simulated expected GVAO was highest in the Southern region compared to all other regions following the 25 percent ( -5 percent) shock in machinery and fertilizer use (labor availability) (Table 3). Counties in the Eastern region also fared well compared to counties in other regions (except those in the Southern region) with respect to an overall increase in GVAO following the technology shock. The median difference between the expected baseline GVAO and the simulated values were similar between counties located in the Northern and Northwestern counties, or counties in the Southwestern and Northeastern regions. Results were also similar with the input shocks simulated as 15 percent (35 percent) increase for fertilizer and machinery use, and a 0 percent (15 percent) decrease in labor availability, with narrower (wider) margins between the differences (not shown).

Local Moran's I statistics of the difference between the expected baseline and simulated GVAO forecasts simulated at the 25 percent increase in machinery and fertilizer and the 5 percent decrease in labor availability were estimated to supplement these comparisons (Figure 4). The global pattern of the differences exhibited negative spatial autocorrelation (global Moran's $I$ $=-0.35, p=.002$ ); counties experiencing relatively large increases in GVAO following the shock are surrounded by counties that experienced a decline in value-added output after the same shock. Administrative units experiencing higher (lower) GVAO following an increase in fertilizer and machinery use and a decrease in labor availability positively (negatively) influence GVAO growth in neighboring counties. In sum, while the expected distribution of the absolute change in GVAO mirrors the spatial distribution of the baseline, the differential change exhibited a pattern of negative spatial autocorrelation. This pattern could be associated with localized inter-county demand for, or availability of, limited inputs. General policies encouraging (or discouraging) the use of capital intensive inputs or labor may, holding other factors constant, alter the GVAO geographic distribution in a pattern similar to the status quo distribution. However, on the margin, a systematic pattern could also emerge between

Southern Regional Science Association 2010. 
FIGURE 2. Local Moran's I Statistics for Predicted GVAO (left) and the Difference between Predicted GVAO and Simulated GVAO after a +25 Percent Increase in Fertilizer and Machinery Capacity, and -5 Percent Labor Decrease (right).

Panel A

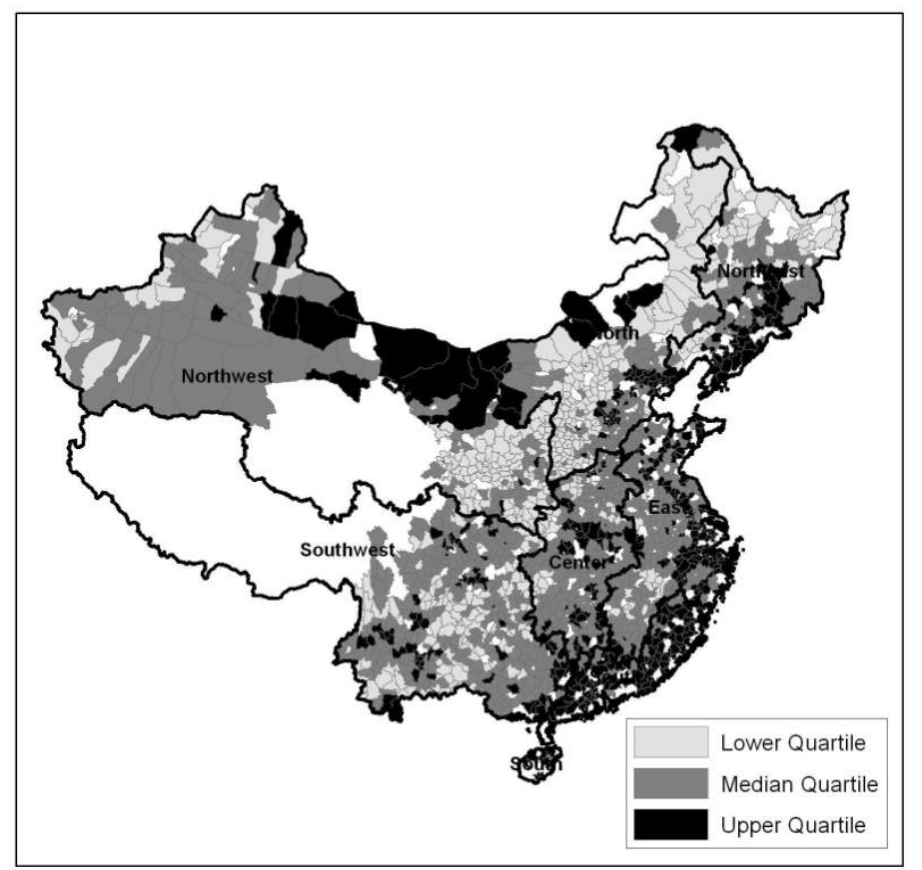

Panel B

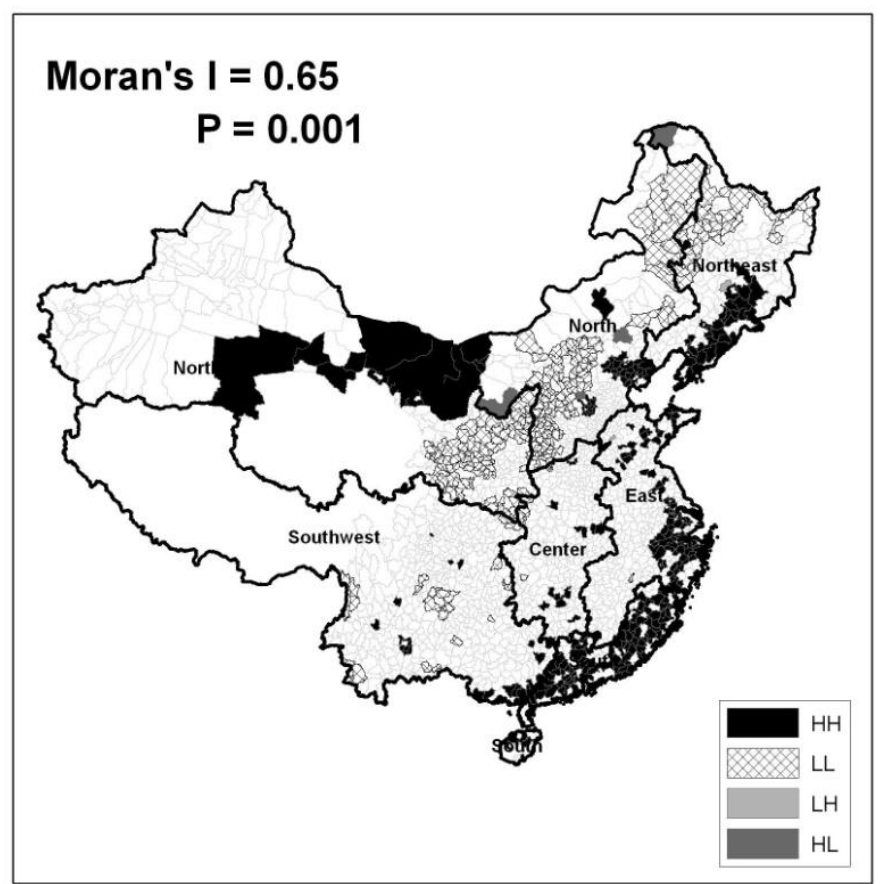

Key: $\mathrm{HH}=$ regions where counties with high GVAO levels were surrounded by other counties with similarly high GVAO, LL = regions where counties with low GVAO levels were surrounded by other counties with similarly low GVAO, LH = regions where counties with low GVAO levels were surrounded by other counties with high GVAO, HL = regions where counties with high GVAO levels were surrounded by other counties with low GVAO. 
FIGURE 3. Moran's I Statistics for Predicted GVAO (left) and the Difference between Predicted GVAO and Simulated GVAO after $+25 \%$ Increase in Fertilizer and Machinery Capacity, and a -5 Percent Labor Decrease (right).
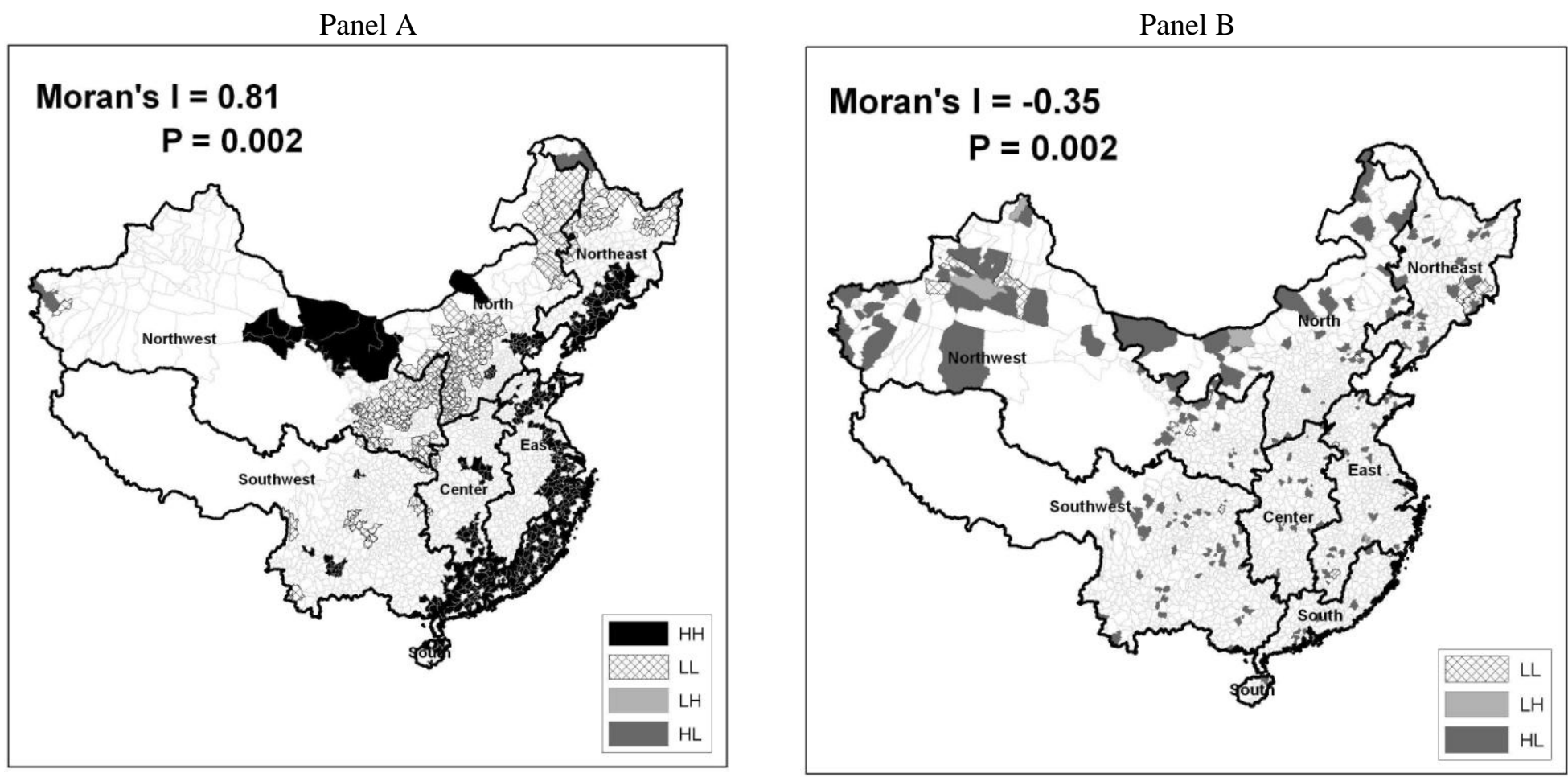

Key: $\mathrm{HH}=$ regions where counties with high GVAO levels were surrounded by other counties with similarly high GVAO, LL = regions where counties with low GVAO levels were surrounded by other counties with similarly low GVAO, LH = regions where counties with low GVAO levels were surrounded by other counties with high GVAO, HL = regions where counties with high GVAO levels were surrounded by other counties with low GVAO. 
TABLE 3. Regional Differences between Base and Simulation, U.S. Dollars per Hectare.*

\begin{tabular}{|c|c|c|c|c|c|c|c|c|}
\hline \multirow[b]{2}{*}{ Region } & \multirow[b]{2}{*}{$\begin{array}{l}\text { Difference } \\
\text { in medians }\end{array}$} & \multirow{2}{*}{$\begin{array}{l}\text { Difference } \\
\text { from } \\
\text { global } \\
\text { median }^{\#}\end{array}$} & \multicolumn{6}{|c|}{ Interregional comparison $^{\dagger}$} \\
\hline & & & East & North & Northeast & Northwest & South & Southwest \\
\hline East & 25.35 & 4.81 & 0.00 & & & & & \\
\hline North & 13.95 & -6.59 & $-11.39 * * *$ & 0.00 & & & & \\
\hline Northeast & 19.39 & -1.15 & $-5.96 * * *$ & $5.44 * * *$ & 0.00 & & & \\
\hline Northwest & 14.37 & -6.17 & $-10.97 * * *$ & 0.42 & $-5.02 * * *$ & 0.00 & & \\
\hline South & 39.83 & 19.29 & $14.48 * * *$ & $25.87 * * *$ & $20.44 * * *$ & $25.45 * * *$ & 0.00 & \\
\hline Southwest & 20.43 & -0.11 & $-4.91 * * *$ & $6.48 * * *$ & 1.04 & $6.06 * * *$ & $-19.39 * * *$ & 0.00 \\
\hline Central & 23.01 & 2.47 & $-2.33 * * *$ & $9.06^{* * *}$ & $3.62 *$ & $8.64 * * *$ & $-16.81 * * *$ & $2.58 * * *$ \\
\hline
\end{tabular}

Notes: ${ }^{*}$ The simulated values were obtained by applying a 25 percent increase in fertilizer and machinery capacity, and a 5 percent decrease in labor availability.

${ }^{+}$The difference between the predicted and simulated median GVAO. The difference is calculated as med $\left(\hat{y}_{\text {Base }}^{\text {GVAO }}\right)-$ med $\left(\hat{y}_{\text {Simulated }}^{\text {GVAO }}\right)$.

\# The country-wide median of the difference between the predicted and simulated GVAO.

$\dagger$ This section of the table provides a cross-regional comparison of the differences in medians between the predicted and simulated GVAO. ***, **, * indicate the median differences are different at the 1,5 , and 10 percent levels, respectively (two sample median test). For example, the entry in the North-East cell is $13.95-25.35=-11.39$. 


\section{FIGURE 4. The Empirical Densities of the Baseline Gross Value Added Agriculture (GVAO) and the Simulated GVAO's Are Not Statistically Different.}

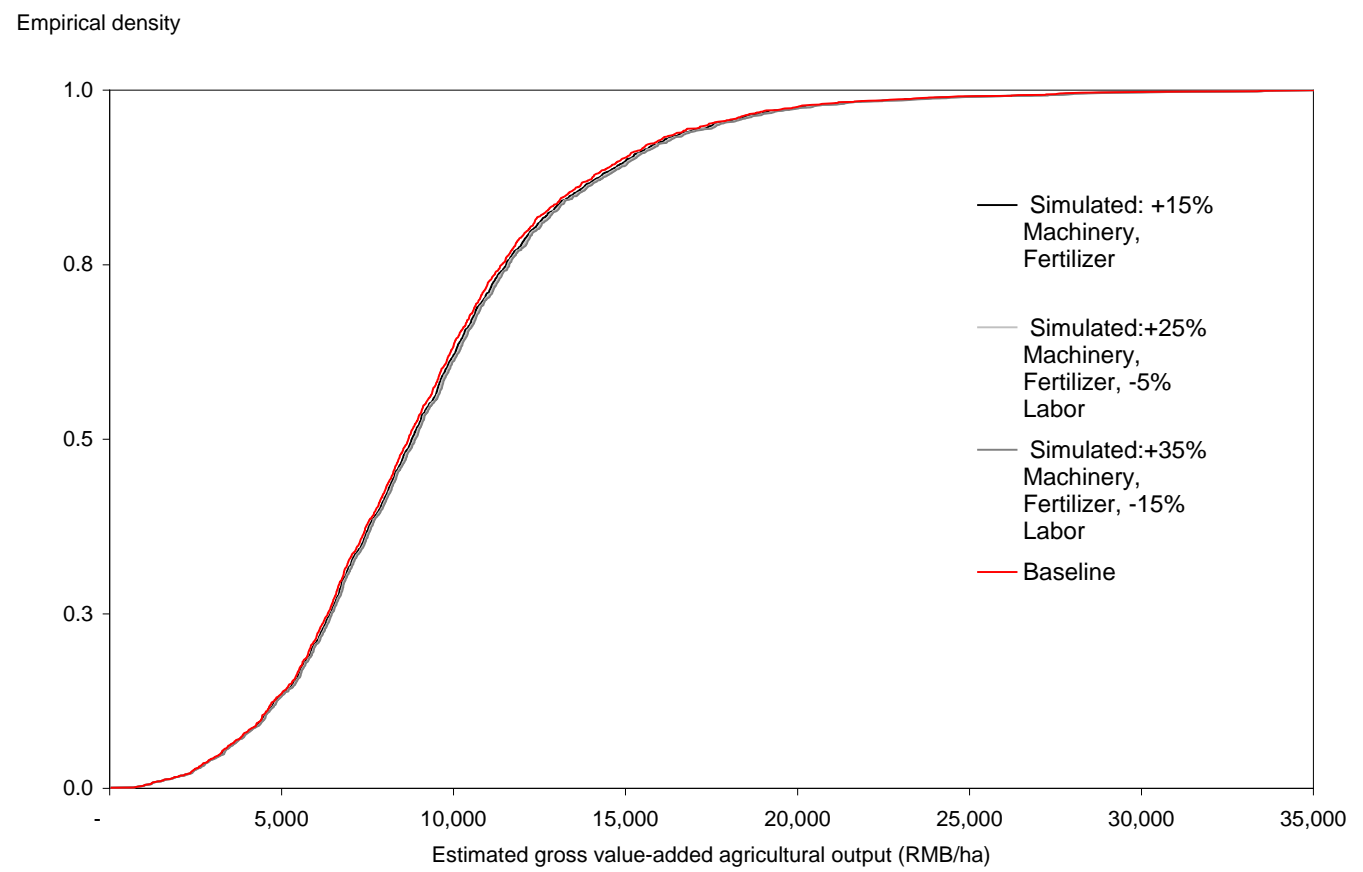

neighboring administrative units where the expected change in one location deviates substantially from the national average (either above or below the central tendency).

\section{CONCLUSIONS}

China's agricultural sector is undergoing rapid changes with respect to input use and increasing agricultural productivity. Many of the changes are attributable to years of economic reform and applied research and extension (Ray 2008), but other changes are occurring in response to demand from domestic and global markets. Citizens are enjoying higher incomes as China's service and manufacturing sectors continue to expand. Rural citizens are more frequently migrating to urban centers to take advantage of new job opportunities and better wages. In the agricultural sector, use of capital intensive inputs is increasing to meet growing demand for staple crops and crops dedicated to animal feed and other value-added uses. But while many citizens continue to relocate in urban areas, most of China's population remains in places where agriculture remains an important component of many rural economies. What remains uncertain is how these changes in input demand will impact the geographic distribution of GVAO, on the one hand, and potential farm income on the other.

This paper applied recent developments in forecasting spatial process models to estimate the impact of GVAO following an input shock in each of China's seven regions. Using a limited set of agricultural input and production data obtained from the Chinese State Statistical Bureau, the study developed a spatial process model whereby anticipated changes in input use and their effect on local gross value-added agricultural output was forecasted. Spatial forecasts were generated following shocks in labor availability and machinery and fertilizer use. The forecasts suggest that the spatial distribution of level changes in GVAO are similar to the baseline GVAO 
values. However, when changes in GVAO were measured as differences from the baseline estimates, there appears to be some regional heterogeneity with respect to the magnitude and direction of the differential supply responses. Production shocks due to increased use in fertilizer or machinery, or the continued emigration of farm labor to cities will generally correspond with an increase in GVAO across China. However, the spatial distribution of these level differences between administrative units may exhibit a pattern of negative spatial autocorrelation. Thus, while across the board increases may be expected following an increase in machinery and fertilizer use and a decrease in labor availability, larger gains in some places may have negative impacts on GVAO in neighboring areas.

Clearly, additional detailed local and regional information is needed to more accurately forecast geospatial changes in China's agricultural following shocks in input use or availability. Future research and data collection efforts along these lines would benefit from information including infrastructural assets, access to localization and urbanization economies, and ruralurban linkages. Panel data or multi-year series could further provide understanding of potential temporal dynamics, as well. Such an approach would add another dimension to estimating the SARAR(1,1) process model in particular and spatial forecasting in general.

\section{REFERENCES}

Abreu, Maria, Henri L.F. De Groot, and Raymond J.G.M. Florax. (2004) "Space and Growth: A Survey of Empirical Evidence and Method," TI 2004-129/3, VU University Amsterdam, Tinbergen Institute Working Paper, last accessed at: http://www.tinbergen.nl, in January 2010.

Anselin, Luc. (1988) Spatial Econometrics: Methods and Models. Kluwer Academic Publishers: Dorddrecht.

. (1995) "Local Indicators of Spatial Association — LISA," Geographical Analysis, 27, 93-115.

(2003) "Spatial Externalities, Spatial Multipliers and Spatial Econometrics," International Regional Science Review, 26, 153-166.

Anselin, Luc, and Raymond J.G.M. Florax. (1995) New Direction in Spatial Econometrics. Springer: Berlin.

Anselin, Luc, and Nancy Lozano-Gracia. (2008) "Error in Variables and Spatial Effects in Hedonic House Price Models of Ambient Air Quality," Empirical Economics, 34, 5-34.

Bao, Shuming, Mark Henry, and David Barkley. (2004) "Identifying Urban-Rural Linkages: Tests for Spatial Effects in the Carlino-Mills Model," Chapter 15 in Luc Anselin, Raymond J.G.M. Florax, and Sergio J. Rey, eds., Advances in Spatial Econometrics: Methodology, Tools and Applications. Springer-Verlag: New York, pp. 321-334.

Bell, Kathleen P., and Nancy E. Bockstael. (2000) "Applying the Generalized-Moments Estimation Approach to Spatial Problems Involving Microlevel Data," Review of Economics and Statistics, 87, 72-82.

Boarnet, Marlon G., Saksith Chalermpong, and Elizabeth Geho. (2005) "Specification Issues in Models of Population and Employment Growth," Papers in Regional Science, 84, 21-46. 
Cai, Fang, Dewen Wang, and Du Yang. (2001) "Labor Market Distortions and Economic Growth: Examining Institutional Components of Regional Disparity in China," Center for Human Resource Studies Working Paper No. 10, Chinese Academy of Social Sciences.

Carter, Colin A., and Scott Rozelle. (2001) "Will China Become a Major Force in World Food Markets?," Review of Agricultural Economics, 23, 319-332.

Cho, Seong-Hoon, Zhuo Chen, Steven T. Yen, and Burton C. English. (2007) "Spatial Variation of Output-input Elasticities: Evidence from Chinese County-level Agricultural Production Data," Papers in Regional Science, 86, 139-157.

Cho, Seong-Hoon, Zhuo Chen, and Neelam C. Poudyal. (2010) "Spatial Structure of Agricultural Production in China," Applied Economics, 42, forthcoming.

Cliff, Andrew D., and John K. Ord. (1973) Spatial Autocorrelation. Pion:London. . (1981) Spatial Processes - Models and Applications. Pion: London.

Cohen, Jeffrey P., and Catherine J. M. Paul. (2005) "Agglomeration Economies and Industry Location Decisions: the Impacts of Spatial and Industrial Spillovers," Regional Science and Urban Economics, 35, 215-237.

Fan, Shenggen. (1997) "How Fast Have China's Agriculture Production and Productivity Really Been Growing?: New Measurement and Evidence," Environment and Production Technology Division (EPTD) Discussion Paper No. 30, International Food Policy Research Institute.

Fan, Shenggen, and Xiaobo Zhang. (2002) "Production and Productivity Growth in Chinese Agriculture: New National and Regional Measures," Economic Development and Cultural Change, 50, 819-838.

Fuller, Frank H., Dermot J. Hayes, and Darnell B. Smith. (2000) "Reconciling Chinese Meat Production and Consumption Data," Economic Development and Cultural Change, 49, 23-44.

Greene, William H. (1997). Econometric Analysis. 3rd edn. Prentice-Hall: Englewood Cliffs, NJ.

Guo, Xuguang, Barry M. Popkin, and Fengying Zhai. (2000) "Patterns of Change in Food Consumption and Dietary Fat Intake in Chinese Adults, 1989-93," Food and Nutrition Bulletin, 20, 344-353.

Hsu, Hsin-Hui, Wen S. Chern, and Fred Gale. (2001) "How Will Rising Income Affect the Structure of Food Demand? In China's Food and Agriculture: Issues for the 21st Century," Agricultural Information Bulletin No. 775, U.S. Department of Agriculture, Economic Research Service, pp. 10-13.

Kelejian, Harry H., and Ingmar R. Prucha. (1999) "A Generalized Moments Estimator for the Autoregressive Parameter in a Spatial Model," International Economic Review, 40, 509533.

. (2007) "The Relative Efficiencies of Various Predictors in Spatial Econometric Models Containing Spatial Lags," Regional Science and Urban Economics, 37, 363-374. 
(2010) "Specification and Estimation of Spatial Autoregressive Models with Autoregressive and Heteroskedastic Disturbances," Journal of Econometrics, forthcoming (available online, October 2010).

Lambert, Dayton M., Patrick Sullivan, Roger Claassen, and Linda Foreman. (2007) "Profiles of US Farm Households Adopting Conservation-Compatible Practices," Land Use Policy, $24,72-88$.

Lu, Feng. (1998) “Output Data on Animal Products in China: How Much Are They Overstated?” An Assessment of Chinese Statistics for Meat, Eggs, and Aquatic Products. China Center for Economic Research, Peking University.

Monchuk, Daniel C., John A. Miranowski, Dermot J. Hayes, and Bruce A. Babcock. (2007) “An analysis of regional economic growth in the U.S. Midwest," Review of Agricultural Economics, 29, 17-39.

Moreno, Rosina, Enrique López-Bazo, Esther Vayá, and Manuel Artis. (2004) "External Effects and Cost of Production," in Luc Anselin, Raymond J.G.M. Florax, and Sergio J. Rey, eds., Advances in Spatial Econometrics: Methodology, Tools and Applications. Springer: Berlin, pp. 297-320.

Ray, Daryll E. (2008) "Since 2000, China has reduced massive rice and wheat stock levels but are now exporters of both," Agricultural Policy Analysis Center, University of Tennessee, Knoxville, TN. Last accessed at: http://agpolicy.org/articles08.html in January 2010.

State Statistical Bureau. (1996-2000) A Statistical Survey of China. Beijing: China Statistical Press.

Tian, Wei-Ming, and John Chudleigh. (1999) "China's Feed Grain Market: Development and Prospects," Agribusiness, 15, 393-409.

Whittle, Peter. (1954) “On Stationary Processes in the Plane,” Biometrika, 41, 434-449.

Wisner, Bob. (2000) “Future Directions of China's Agricultural Production," Doane's Agricultural Service Report, 63, 32-35.

Yang, Ling and Michael L. Lahr. (2009) "Labor Productivity Differences in China, 1987-1997: An Interregional Decomposition Composition Analysis," Review of Regional Studies, 38, 319-341 (this issue).

Zhong, Funing. (1997) "Will China Increase Feed Grain Imports: An Assessment of China's Meat Production and Consumption Statistics," Paper presented at the International Food Policy Research Institute, Washington, D.C. 